\title{
Analysis and Design of Ultra-Wideband 3-Way Bagley Power Divider Using Tapered Lines Transformers
}

\author{
Khair Al Shamaileh, ${ }^{1}$ Abdullah Qaroot, ${ }^{2}$ Nihad Dib, ${ }^{3}$ \\ Abdelfattah Sheta, ${ }^{4}$ and Majeed A. Alkanhal ${ }^{4}$ \\ ${ }^{1}$ Waseela for Integrated Telecommunication Solutions, P.O. Box 962487, Amman 11196, Jordan \\ ${ }^{2}$ Electrical Engineering Department, King Faisal University, P.O. Box 400, Al-Ahsa 31982, Saudi Arabia \\ ${ }^{3}$ Electrical Engineering Department, Jordan University of Science and Technology, P.O. Box 3030, Irbid 22110, Jordan \\ ${ }^{4}$ Electrical Engineering Department, King Saud University, P.O. Box 800, Riyadh 11421, Saudi Arabia
}

Correspondence should be addressed to Khair Al Shamaileh, khair.shamaileh@waseela-net.com

Received 26 October 2011; Accepted 11 April 2012

Academic Editor: Walter De Raedt

Copyright ( $) 2012$ Khair Al Shamaileh et al. This is an open access article distributed under the Creative Commons Attribution License, which permits unrestricted use, distribution, and reproduction in any medium, provided the original work is properly cited.

An ultra-wideband (UWB) modified 3-way Bagley polygon power divider (BPD) that operates over a frequency range of 2-16 GHz is presented. To achieve the UWB operation, the conventional quarter-wave transformers in the BPD are substituted by two tapered line transformers. For verification purposes, the proposed divider is simulated, fabricated, and measured. The agreement between the full-wave simulation results and the measurement ones validates the design procedure.

\section{Introduction}

Recently, the need for microwave components that have the capability of operating over a wide range of frequencies has motivated many researchers. Thus, many papers that investigate the ultra-wide operation for different microwave devices such as the Wilkinson power dividers (WPDs), branch line couplers (BLCs), and antennas were proposed. In [1], an UWB directional coupler that operates over a frequency range of $3.1-10.6 \mathrm{GHz}$ was presented. To realize such an UWB coupler, two elliptically shaped microstrip lines, which are broadside coupled through an elliptically shaped slot, were used. In [2], a similar approach was used to design a slot-coupled multisection quadrature hybrid coupler for UWB applications. A novel approach for the design of UWB $3 \mathrm{~dB}$ couplers, out-of-phase equal-split power dividers, omnidirectional monopole antennas, and directional tapered slot antennas was proposed in [3]. In [4], a novel UWB WPD with modifications on the traditional divider by adding an extra open stub on each branch was proposed. In [5], an UWB WPD that consists of two branches of impedance transformers, each one consisting of two sections of transmission lines with different characteristic impedances and different lengths, was proposed. A modified UWB WPD formed by implementing one delta stub on each branch was proposed in [6]. In [7], and based on the theory presented in [8], a WPD that operates over a frequency range of $2-10.2 \mathrm{GHz}$ was designed by substituting its conventional quarter-wave arms by tapered lines. Three resistors were added along the tapered lines to achieve an acceptable isolation between the output ports.

One of the power dividers, which has been a new area of research, is the Bagley polygon power divider (BPD) [9-17]. Compared to other power dividers, such as the Wilkinson power divider, Bagley polygon power divider does not use lumped elements, such as resistors, and can be easily extended to any number of output ports. However, the output ports for such dividers are not matched, and the isolation between them is not as good as that of the Wilkinson power divider. In [9], reduced size 3-way and 5way Bagley power dividers (BPDs), using open stubs, were presented. In [10], an optimum design of a modified 3way Bagley rectangular power divider was investigated. In $[11,12]$, a general design of compact multiway dividers based 


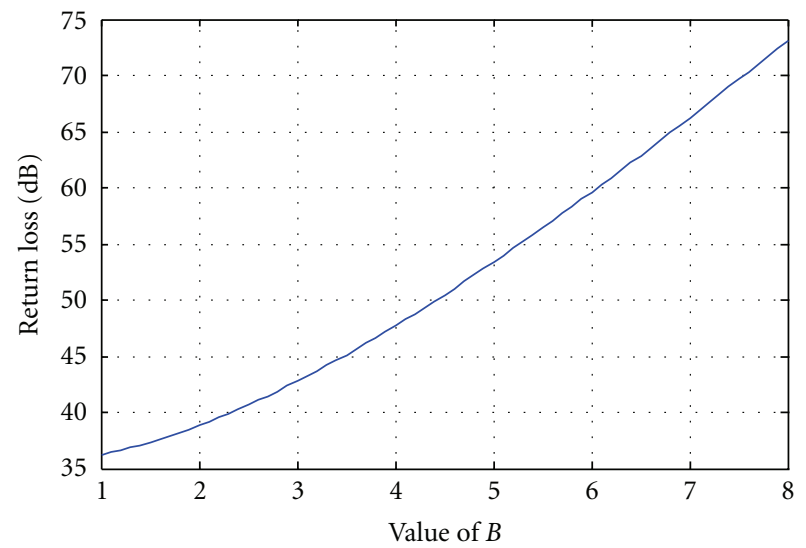

Figure 1: The obtained input return loss (in $\mathrm{dB}$ ) versus $B$ for $Z_{s}=100 \Omega$ and $Z_{l}=33.333 \Omega$.

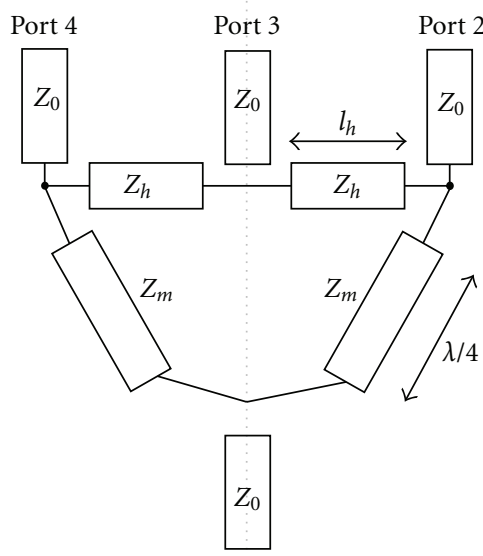

Port 1

(a)

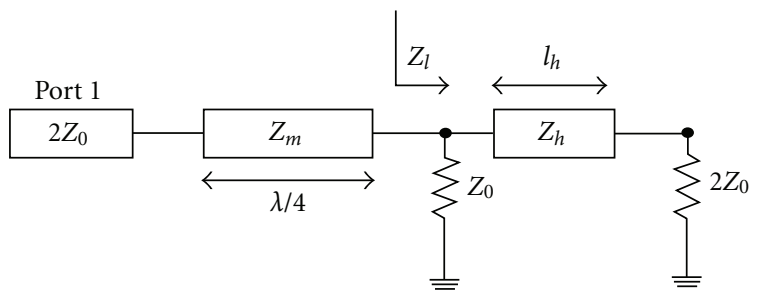

(b)

FIGURE 2: Schematic diagram of the 3-way BPD and its equivalent circuit.

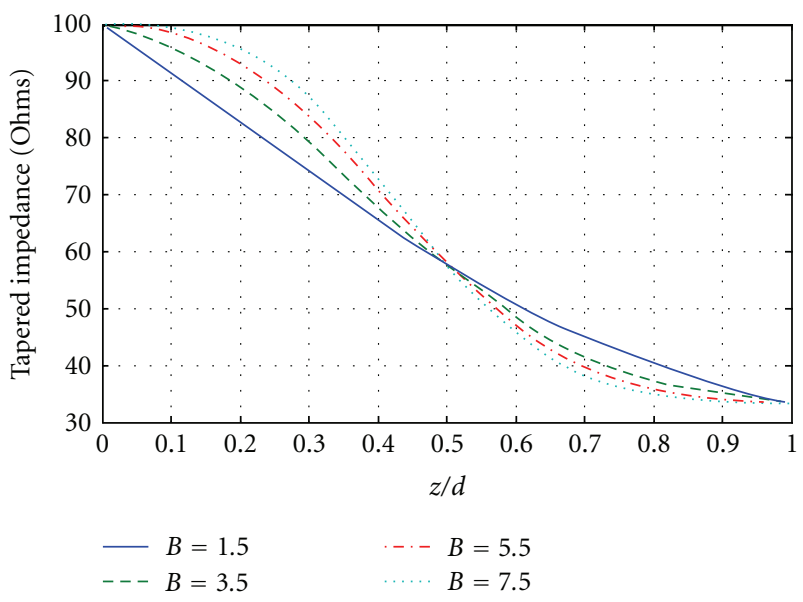

Figure 3: The tapered impedance variation for different values of $B$.

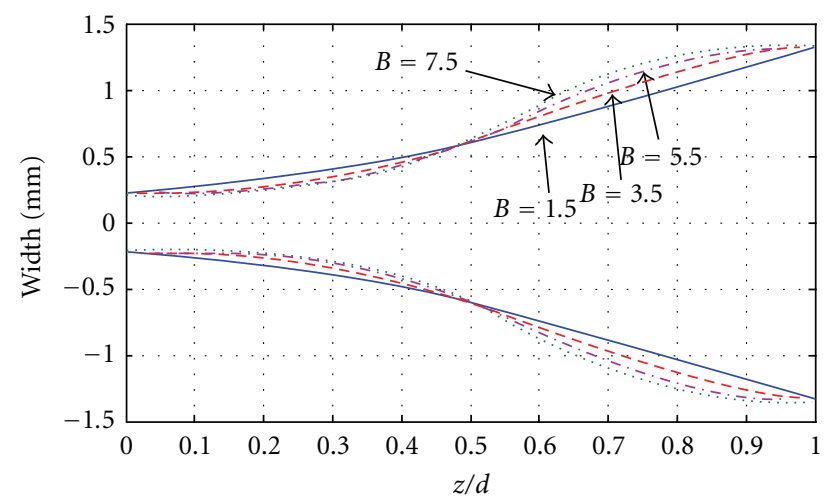

FIGURE 4: The tapered line width variation for different values of $B$.

on BPDs was introduced. In [13], a compact dual-frequency 3-way BPD using composite right-/left-handed (CRLH) 


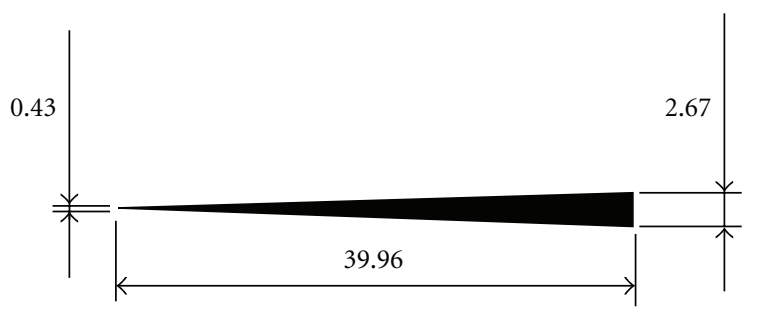

(a)

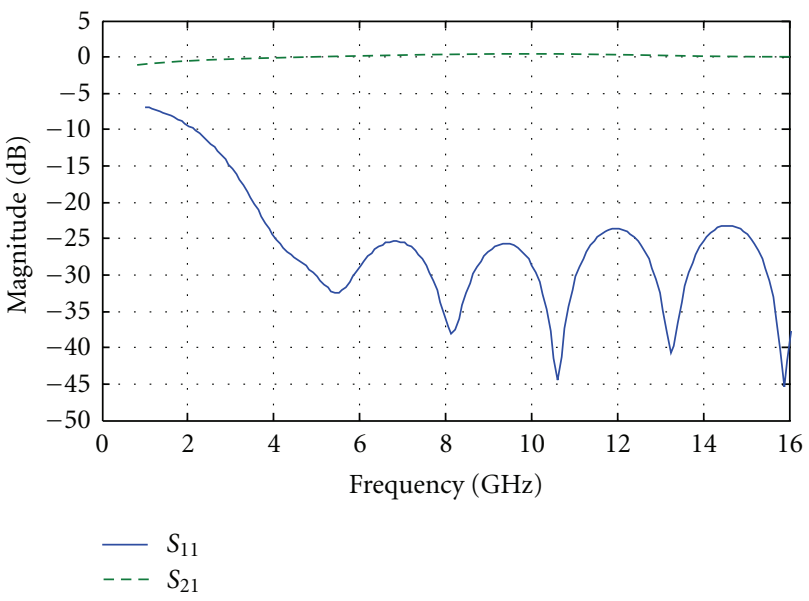

(b)

FIgURE 5: (a) The designed UWB tapered line transformer (dimensions are in $\mathrm{mm}$ ). (b) The input port matching parameter $S_{11}$ and the transmission loss parameter $S_{21}$.

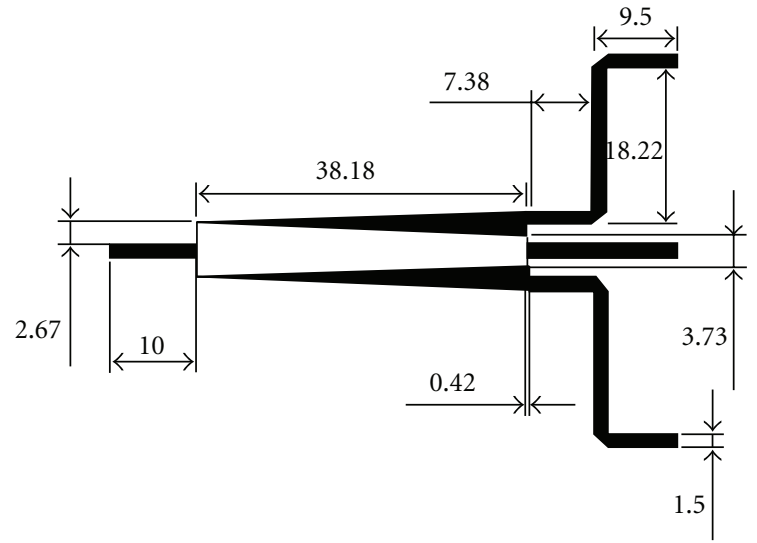

FIGURE 6: The layout of the proposed UWB 3-way BPD (dimensions are in $\mathrm{mm}$ ).

transmission lines was implemented. Recently, and based on the generalized 3-way Bagley polygon power divider, dualpassband filter section was presented in [14]. Moreover, compact 5-way BPD for dual-band (or wide-band) operation was proposed in [15]. Dual-band modified 3-way BPDs based on substituting the quarter-wave sections of the conventional design by their equivalent dual-band matching networks were presented in [16]. Very recently, multiband miniaturized 3-way and 5-way BPDs were proposed in [17]. It should be mentioned here that all of the BPDs investigated in [9-17] have an odd number of output ports. In [18], a novel approach for the design of modified BPDs with even number of output ports was proposed.

In this paper, an UWB modified 3-way BPD that operates over the frequency range of $2-16 \mathrm{GHz}$ is presented. To have such a divider, the quarter-wave sections are substituted by their equivalent UWB tapered lines. The designed UWB divider is simulated using two full-wave EM simulators. Moreover, the divider is fabricated and measured, and the simulation and measurement results are in a good agreement.

\section{Tapered Line Design}

According to $[7,8]$, the maximum input return loss (in $\mathrm{dB}$ ) for a given tapered line that is used in order to match a source impedance $Z_{s}$ to a load impedance $Z_{l}$ is given by the following equation:

$$
\begin{aligned}
& \left|R L_{\text {input }}\right|_{\text {max }} \\
& \quad=-20 \log \left[\tanh \left(\frac{B}{\sinh B}(0.21723) \ln \left(\sqrt{\frac{Z_{l}}{Z_{s}}}\right)\right)\right],
\end{aligned}
$$

where $B$ is a predefined design parameter used to determine the tapered line curve. Figure 1 shows the effect of increasing $B$ on the obtained input return loss.

As seen from Figure 1, larger values of $B$ result in lower reflection at the input port. However, increasing $B$ will demand wider tapered line width and longer length.

After choosing the value of $B$ in order to achieve a desired input return loss, the exponential tapered line characteristic impedance is calculated using the following equations $[7,8]$ :

$$
\ln \left(\frac{Z(z)}{Z_{s}}\right)=0.5 \ln \left(\frac{Z_{l}}{Z_{s}}\right)\left[1+G\left(B, 2\left(\frac{z}{d}-0.5\right)\right)\right],
$$

where

$$
G(B, \xi)=\frac{B}{\sinh B} \int_{0}^{\xi} I_{0}\left(B \sqrt{1-\xi^{\prime 2}}\right) d \xi^{\prime}
$$

It should be mentioned here that $Z(z)$ in $(2 \mathrm{a})$ represents the characteristic impedance of the tapered line at point $z$, and $I_{0}(x)$ represents the modified zero-order Bessel function. The tapered line length $d$ is a predefined variable chosen appropriately to achieve the desired maximum return loss. 


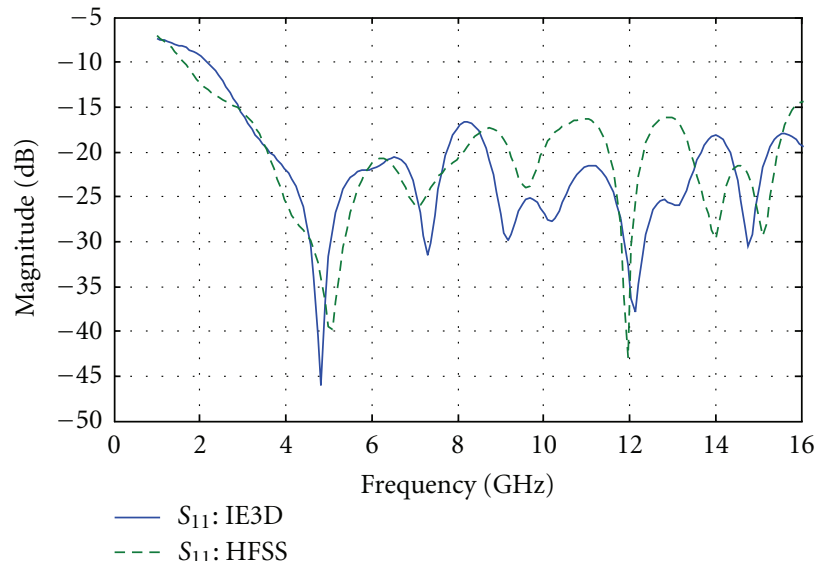

(a)

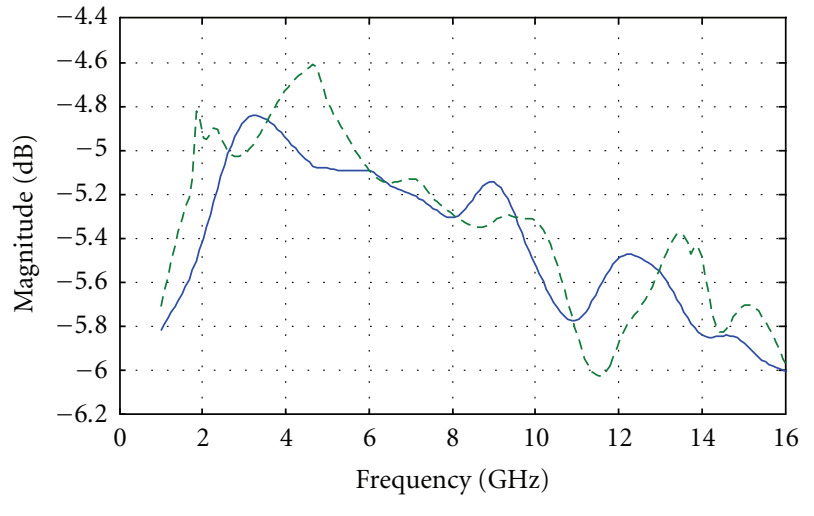

$-S_{21}:$ IE3D

(b)

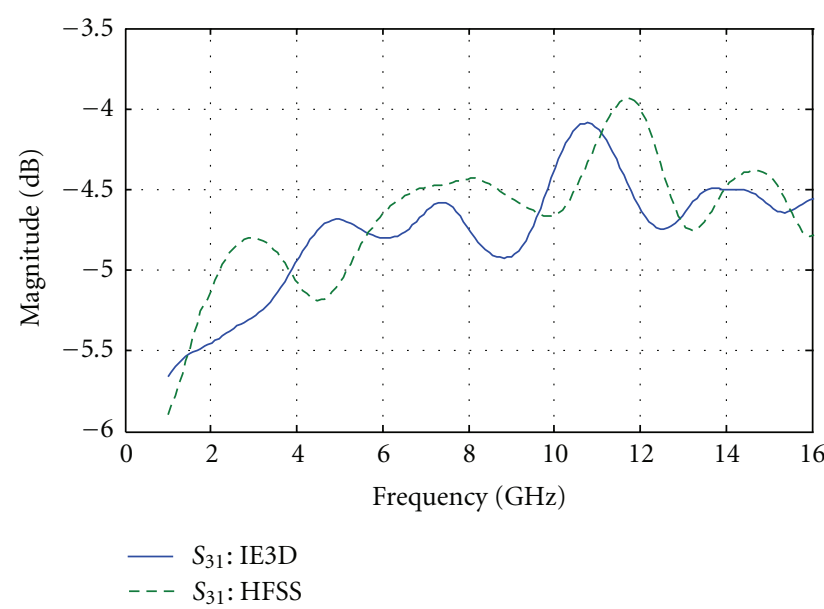

(c)

FIgURE 7: Simulated scattering parameters for the designed UWB BPD.

\section{UWB 3-Way BPD Design}

In this section, the design of a modified UWB 3-way BPD is presented. Figure 2(a) shows the schematic diagram of the 3-way modified BPD [11]. Noting that this divider is symmetric around its center line, an equivalent circuit (looking from port 1 to the right or left side) can be drawn as shown in Figure 2(b).

Referring to the equivalent circuit, it can be easily realized that choosing $Z_{h}=2 Z_{0}$ makes the design of this BPD independent of the length $l_{h}$. In this case, the characteristic impedance $\left(Z_{m}\right)$ of the quarter wave section is $Z_{m}=$ $\sqrt{\left(2 Z_{0}\right) Z_{l}}$, where $Z_{l}=2 Z_{0} / 3$. This gives

$$
Z_{m}=\frac{\left(2 Z_{0}\right)}{\sqrt{3}}
$$

Thus, each quarter-wave section matches a load impedance of $Z_{l}=2 Z_{0} / 3$ to a source impedance of $Z_{s}=2 Z_{0}$, resulting in a perfect match at port 1 (the input port) and equal split power division to the three output ports. As noted in the Introduction, the BPD does not contain any lumped elements, and it can be easily extended to any number of output ports.

Now, considering a characteristic impedance of $50 \Omega$, the values of $Z_{s}$ and $Z_{l}$ are $100 \Omega$ and $33.333 \Omega$, respectively. These values will be incorporated in the tapered line design equations given in (1) and (2a). Then, the resulting tapered line will replace each conventional quarter-wave transmission line transformers in the BPD presented in Figure 2 in order to obtain an UWB operation. Figure 3 shows the variation of the tapered impedance for different values of $B$, which can be translated into microstrip width variation as shown in Figure 4. It is worth mentioning here that the substrate used in order to obtain the tapered line width for all cases is Duroid RT5870 with a relative permittivity $\varepsilon_{r}=$ 2.33 , a thickness of $0.508 \mathrm{~mm}$, and a loss tangent of 0.0012 .

It can be seen from Figures 3 and 4 that larger values of $B$ result in a wider microstrip line width. In our design, $B$ is chosen to be 5.5, which corresponds to a maximum input return loss of $56.44 \mathrm{~dB}$. The length of the designed tapered line is set to $40 \mathrm{~mm}$, which is about 1.48 times the length of the conventional transmission line transformer at the lower 


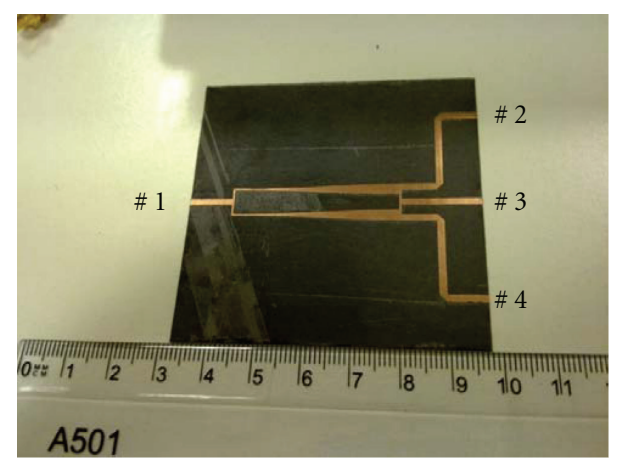

FIgURE 8: The photograph of the fabricated divider.

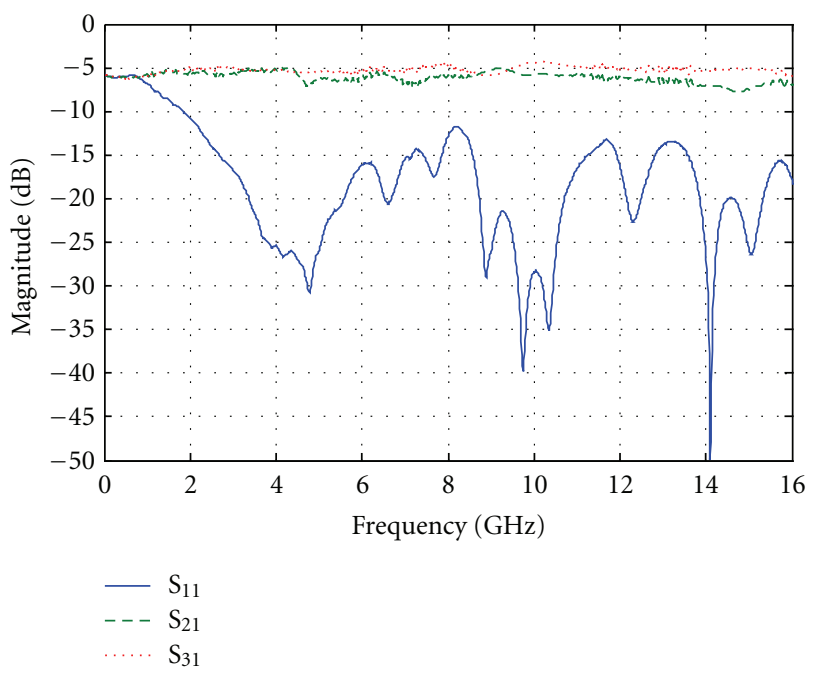

FIGURE 9: Measured scattering parameters of the divider shown in Figure 8.

frequency $(2 \mathrm{GHz})$. However, such slight increase in the circuitry size leads to obtaining the desired electrical performance, especially the input port matching and transmission parameters performances, not only at a single frequency, but also over a considerable wide range of $2-16 \mathrm{GHz}$. Figure 5 (a) shows the designed tapered transformer that matches a source impedance of $100 \Omega$ to a load impedance of $33.333 \Omega$ along with its obtained input port matching parameter $\left(S_{11}\right)$ and transmission loss parameter $\left(S_{21}\right)$ shown in Figure 5(b). An input return loss better than $10 \mathrm{~dB}$ is obtained over a frequency range of $2-16 \mathrm{GHz}$ for the designed transformer. Moreover, the transmission coefficient $S_{21}$ equals to $-0.2 \mathrm{~dB}$ over the entire frequency range. It is worth to point out here that these results were obtained using the full-wave simulator IE3D [19].

\section{Simulation Results}

Figure 6 shows the layout of the designed UWB modified 3-way BPD. This proposed divider is simulated using two different full-wave electromagnetics simulators: IE3D [19]; which solves Maxwell's equations using the method of moments (MoM), and HFSS [20]; which solves the same equations using the finite element method. Figure 7 shows the obtained scattering parameters.

Figure 7 (a) shows that an input return loss better than $10 \mathrm{~dB}$ is achieved over the frequency range of $2-16 \mathrm{GHz}$. Moreover, the resulting transmission parameter $S_{21}$ (which is equals to $S_{41}$ because of the symmetry of the structure) is close to its theoretical value of $-4.7 \mathrm{~dB} \pm 1 \mathrm{~dB}$ over the same frequency range except for the increase in the losses at higher frequencies. Such losses can be decreased through the use of low-loss tangent substrates. The transmission parameter $S_{31}$ is also close to its theoretical value $(-4.7 \mathrm{~dB} \pm 0.8 \mathrm{~dB})$ over the frequency band $2-16 \mathrm{GHz}$. The discrepancies between the results of the two simulators are thought to be due the different technique each simulator follows to solve Maxwell's equations, and the way the structure was divided in the meshing process during the simulations.

\section{Measurement Results}

The circuit layout shown in Figure 6 is implemented on the same substrate mentioned in Section 3 (Duroid RT5870 with a relative permittivity $\varepsilon_{r}=2.33$ and a thickness of $0.508 \mathrm{~mm}$ ). The extended ports in the circuit layout have been chosen to allow accurate $S$-parameter measurements using universal test fixture (GigaLane) without soldering. A photograph of the fabricated circuit is shown in Figure 8. The measurements have been performed using Anritsu 37369C network analyzer. The measured results are shown in Figure 9. The measured return loss is better than $10 \mathrm{~dB}$ from 2 to $16 \mathrm{GHz}$. The measured $S_{31}$ is almost flat, around $-5 \mathrm{~dB}$, in the entire band. It changes at a few bands to $-6 \mathrm{~dB}$ and some others to $-4.5 \mathrm{~dB}$. On the other hand, the measured $S_{21}$ is approximately $-5.6 \pm 0.7 \mathrm{~dB}$ from $2 \mathrm{GHz}$ to $12 \mathrm{GHz}$ except at $4.8 \mathrm{GHz}$ and $7 \mathrm{GHz}$, where it reaches $-7.2 \mathrm{~dB}$. From $12.5 \mathrm{GHz}$ to $16 \mathrm{GHz}, S_{21}$ changes from $-6 \mathrm{~dB}$ to $-7 \mathrm{~dB}$; except for a small notch at about $15 \mathrm{GHz}$ at which $S_{21}$ is about $-7.7 \mathrm{~dB}$.

\section{Conclusions}

In this paper, an UWB 3-way BPD using tapered line transformers was designed, simulated, fabricated, and measured. Simulation results show a very good performance of the designed divider over a frequency range of $2-16 \mathrm{GHz}$. Measurement results show an acceptable performance with little discrepancies from the simulation ones. These differences could be mainly due to the fabrication process, as well as, measurement errors.

\section{References}

[1] A. M. Abbosh and M. E. Bialkowski, "Design of compact directional couplers for UWB applications," IEEE Transactions on Microwave Theory and Techniques, vol. 55, no. 2, pp. 189194, 2007.

[2] A. Moscoso-Martir, J. G. Wanguemert-Perez, I. Molina-Fernandez, and E. Marquez-Segura, "Slot-coupled multisection quadrature hybrid for UWB applications," IEEE Microwave 
and Wireless Components Letters, vol. 19, no. 3, pp. 143-145, 2009.

[3] M. Bialkowski, A. Abbosh, and H. Kan, "Design of compact components for ultra wideband commiunication front ends," in Proceedings of the NEWCOM-ACoRN Joint Workshop, Vienna, Austria, 2006.

[4] X. P. Ou and Q. X. Chu, "A modified two-section UWB Wilkinson power divider," in Proceedings of the International Conference on Microwave and Millimeter Wave Technology (ICMMT '08), pp. 1258-1260, April 2008.

[5] L. Yang and Q. X. Chu, "Design of a compact UWB Wilkinson power divider," in Proceedings of the International Conference on Microwave and Millimeter Wave Technology (ICMMT'08), pp. 360-362, April 2008.

[6] B. Zhou, H. Wang, and W.-X. Sheng, "A modified UWB Wilkinson power divider using delta stub," Progress In Electromagnetics Research Letters, vol. 19, pp. 49-55, 2010.

[7] C.-T. Chiang and B.-K. Chung, "Ultra wideband power divider using tapered line," Progress in Electromagnetics Research, vol. 106, pp. 61-73, 2010.

[8] R. P. Hecken, "A near optimum matching section without discontinuities," IEEE Transactions on Microwave Theory and Techniques, vol. 20, no. 11, pp. 734-739, 1972.

[9] T. Wuren, K. Taniya, I. Sakagami, and M. Tahara, "Miniaturization of 3- and 5- way Bagley Polygon power dividers," in Proceedings of the Asia-Pacific Microwave Conference (APMC '05), vol. 5, December 2005.

[10] H. Oraizi and S. A. Ayati, "Optimum design of a modified 3way bagley rectangular power divider," in Proceedings of the 10th Mediterranean Microwave Symposium (MMS '10), pp. 2528, August 2010.

[11] I. Sakagami, T. Wuren, M. Fujii, and M. Tahara, "Compact multi-way power dividers similar to the Bagley Polygon," in Proceedings of the IEEE MTT-S International Microwave Symposium (IMS '07), pp. 419-422, June 2007.

[12] I. Sakagami, T. Wuren, M. Fujii, and Y. Tomoda, "A new type of multi-way microwave power divider based on Bagley Polygon power divider," in Proceedings of the Asia-Pacific Microwave Conference (APMC '06), pp. 1353-1356, December 2006.

[13] D. S. Elles and Y. K. Yoon, "Compact dual band three way bagley polygon power divider using Composite Right/Left Handed (CRLH) transmission lines," in Proceedings of the IEEE MTT-S International Microwave Symposium (IMS '09), pp. 485-488, June 2009.

[14] R. Gómez-García and M. Sánchez-Renedo, "Application of generalized Bagley-polygon four-port power dividers to designing microwave dual-band bandpass planar filters," in Proceedings of the IEEE MTT-S International Microwave Symposium (MTT'10), pp. 580-583, May 2010.

[15] I. Sakagami and T. Wuren, "Compact multi-way power dividers for dual-band, wide-band and easy fabrication," in Proceedings of the IEEE MTT-S International Microwave Symposium (IMS '09), pp. 489-492, June 2009.

[16] A. M. Qaroot, K. Shamaileh, and N. Dib, "Design and analysis of dual-frequency modified 3-way Bagley power dividers," Progress In Electromagnetics Research C, vol. 20, pp. 67-81, 2011.

[17] K. A. Al Shamaileh, A. Qaroot, and N. Dib, "Non-uniform transmission line transform-ers and their application in the design of compact multi-band bagley power dividers with harmonics suppression," Progress in Electromagnetics Research, vol. 113, pp. 269-284, 2011.

[18] K. A. Al Shamaileh, A. Qaroot, and N. Dib, "Design of Nway power divider similar to the Bagley polygon divider with an even number of output ports," Progress In Electromagnetics Research C, vol. 20, pp. 83-93, 2011.

[19] 2006, http://www.mentor.com/electromagnetic-simulation/.

[20] HFSS: High Frequency Structure Simulation based on Finite Element Method, V. 10, Ansoft Corporation, http://www.ansys .com/. 

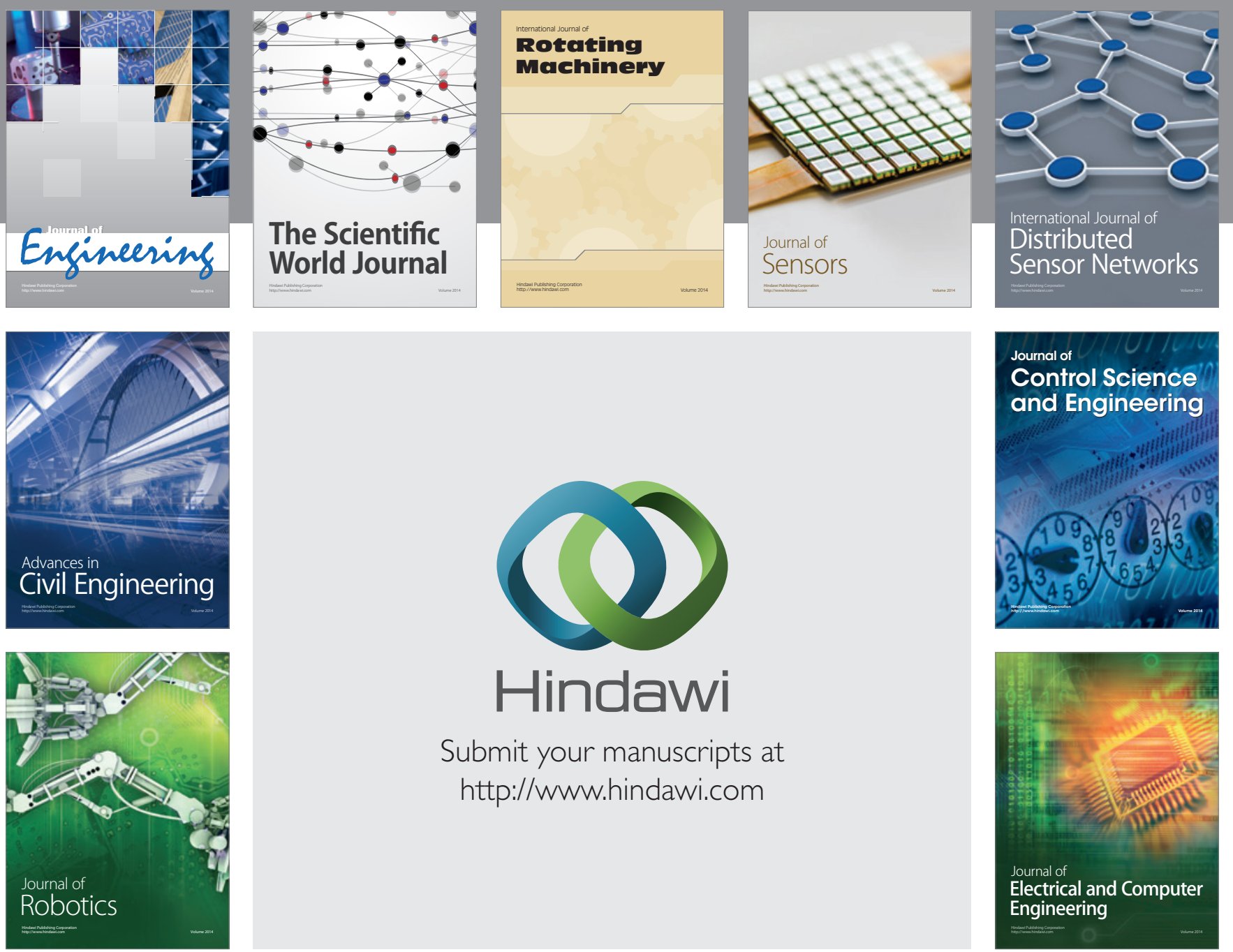

Submit your manuscripts at

http://www.hindawi.com
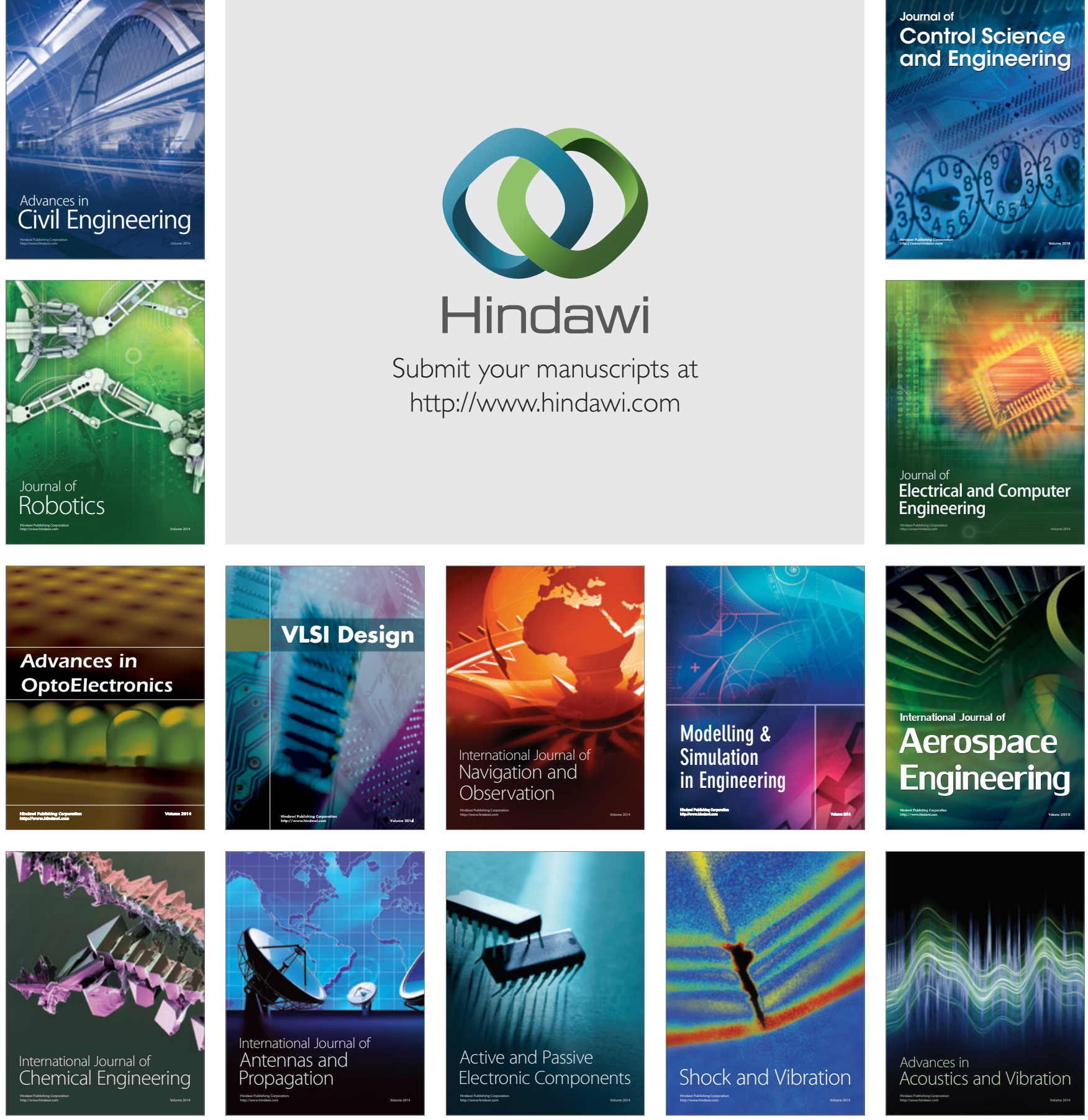